\title{
Akut Apandisit Hastalarında Ortalama Trombosit Volümü (MPV) ve Trombosit Dağılım Genişliği (PDW) Düzeylerinin Tanısal Değeri
}

\author{
Fatma TORTUM, Atıf BAYRAMOĞLU
}

Atatürk Üniversitesi Tıp Fakültesi Acil Tıp Anabilim Dalı, Erzurum.

\begin{abstract}
ÖZET
Bu çalışmada, acil servise karın ağrısı şikayetiyle başvuran, AA tanısı ile opere olan hastalar ile cerrahi tedavi yapılmadan taburcu edilen hastaların ayırıcı tanısında MPV ve PDW parametrelerinin rolü araştırılması amaçlanmıștır. AA tanısıyla yatırılan hastalar retrospektif olarak incelendi. Apendektomi olan ve patoloji raporları AA ile uyumlu olan hastalar AA (+), apendektomi olmayı medikal tedavi sonrası taburcu edilen hastalar AA (-) olarak gruplandırıldı. Hastaların, acil servise başvuru anındaki hemogram sonuçlarına elektronik hasta dosyalarından ulaşıldı. Verilerin istatistiği SPSS 20 paket programı ile yapıldı. Değerlendirilen hastaların (1061) \%46.6'sı kadın (494), \%53.4'ü (567) erkekti. Hastaların \%83.6's1 (888) AA (+), \%16.2'si (173) AA (-) grubundadır. Hastaların AA (+) gruptaki yas ortalamas1 (35 \pm 16$)$, AA (-)

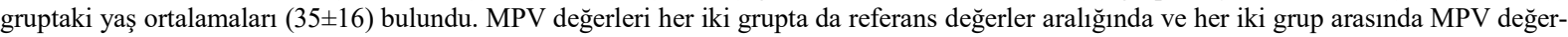
leri arasında anlamlı bir fark yoktu $(\mathrm{P}=0.717)$. PDW değerleri AA $(+)$ hasta grubunda istatistiksel olarak anlamlı olup, düşük bulundu $(\mathrm{P}<0.05)$. AA $(+)$ hasta grubu ile AA (-) hasta grubunu birbirinden ayırmak için MPV'nin anlamsız olduğu görüldü. PDW değerleri AA (+) hasta grubunda düşük ve istatistiksel olarak anlamlı bulundu.
\end{abstract}

Anahtar Kelimeler: Akut apandisit. Akut batın. Ortalama trombosit volümü. Trombosit dağılım genişliği.

Diagnostic Value of Mean Platelet Volume (MPV) and Platelet Distribution Width (PDW) Levels in Patients with Acute Appendicitis

\begin{abstract}
We aimed investigation of the role of MPV and PDW parameters in the differential diagnosis of patients who admitted to the emergency department with the complaint of abdominal pain, patients who were operated with the diagnosis of AA, and patients who were discharged without surgical treatment. Patients hospitalized with an AA diagnosis were analyzed retrospectively. Patients who underwent appendectomy and whose pathology reports were consistent with AA were grouped as AA $(+)$, while patients who did not undergo appendectomy and were discharged after medical treatment were grouped as AA (-). The patients' first hemogram parameters at the emergency service were acquired from their electronic patient files. Statistical analysis of the data was performed using the SPSS 20 package software. Of the eveluated patients, \%83.6 (888) were in the AA (+) group, while \%16.2 (173) were in the AA (-) group. Of the evaluated patients, \%46.6 (494) were female, and \%53.4 (567) were male. The mean age of the patients in the AA ( + ) group $(35 \pm 16)$ and the mean age in the AA $(-)$ group $(35 \pm 16)$ were found. There was no significant difference in MPV values between the two groups $(\mathrm{P}=0.717)$. $\mathrm{PDW}$ values were statistically significant and lower in the AA $(+)$ patient group $(\mathrm{P}<0.05)$. MPV was found to be insignificant in differentiating between the AA $(+)$ patients and the AA (-) patients. In the AA (+) patient group, PDW values were lower and statistically significant.
\end{abstract}

Key Words: Acute appendicitis. Acute abdomen. Mean platelet volüme. The platelet distribution width.

Geliş Tarihi: 06.Eylül.2021

Kabul Tarihi: 19.Kasım.2021

Dr. Fatma TORTUM

Atatürk Üniversitesi Tıp Fakültesi,

Acil Tıp Anabilim Dalı,

Erzurum.

Tel: 05072377148

E-posta: drcitirik@hotmail.com

Yazarların ORCID Bilgileri:

Fatma TORTUM: 0000-0002-1876-5998

Atıf BAYRAMOĞLU: 0000-0003-3053-1956
Akut apandisit (AA), en sik acil cerrahi nedenlerinden biridir. Prevelansı yaklaşık \%7 kadardır. Sık görülmesine rağmen yanlış AA tanısı veya tanıda gecikme oranları yüksektir ${ }^{1}$.

Günümüzde tanı amaçlı birçok yöntem kullanılmaktadır. Bilgisayarlı tomografi (BT) AA tanısında oldukça yüksek sensitivite ve spesifiteye sahiptir. Tanıda BT kullanılması negatif apendektomi oranlarını azaltmış$\mathrm{tır}^{2}$. Ancak BT çekilirken oluşan radyasyon maruziyeti ve çekim esnasında kontrast madde kullanımı BT kullanımını kısıtlamaktadır. Klinik bulgular, skorlamalar ve radyolojik görüntülemelerin yanında biyokimyasal, hematolojik parametreler de tanı amaciyla 
kullanılmaktadır. AA tanısında kullanılan parametrelerden lökosit (WBC), C-reaktif protein (CRP) veya prokalsitonin gibi inflamatuvar belirteçlerin hiçbiri AA tanısında yüksek sensitivite ve spesifiteye sahip değildirler ${ }^{3}$.

Ortalama trombosit volümü, dolaşımda bulunan trombositlerin ortalama boyutunun ölçümüdür. Trombosit üretimi azaldığında, genç trombositler daha büyük ve daha aktif hale gelir. MPV seviyeleri artar. PDW, trombositlerin volüm değişkenliğinin bir göstergesidir ve trombosit anisositozu varlığında $\operatorname{artar}^{4}$. Trombosit boyutu arttıkça aktivitesi artacağından trombositler boyutlarını artırmak için psödopodlar oluşturur. Psödopodların oluşmasına bağlı trombosit anisositozu artar, PDW değeri yükselir, ${ }^{4,5}$. Aslında her iki parametre de trombosit aktivitesinin ve immatüritesinin belirtecidir. Trombosit ölçüleri ve aktivitesi IL-3 ve IL-6 gibi inflamatuvar sitokinlerden etkilenmektedir ${ }^{6}$. Bu nedenle MPV ve PDW değerleri inflamatuvar süreçlerden etkilenir ${ }^{7}$.

Akut apandisit tanısı ile cerrahi olarak müdahale edilen hastaların \%5-30'unda appendiksin perfore olduğu görülmektedir. Ancak aynı zamanda apendektomiye giden AA şüpheli hastaların da \%5-40'1nda appendiks normaldir ${ }^{2}$. Gereksiz apendektomileri, tanıda gecikme ve komplikasyonları önlemek için kolay uygulanan, ucuz yöntemler geliştirilmelidir. Bu amaçla acilde AA tanısı alan hastalar incelenmiştir. AA tanısı ile opere edilen hastalar ile operasyon yapılmadan, medikal takip sonrası taburcu edilen hastaların ayırıcı tanısında MPV ve PDW parametrelerinin rolü araştırılmıştır.

\section{Gereç ve Yöntem}

Çalışma Atatürk Üniversitesi Tıp Fakültesi hastanesi acil servisinde retrospektif olarak yapılmıştır. Çalışma için Atatürk Üniversitesi Tıp Fakültesi Klinik Araştırmalar Etik Kurulu'ndan onay alınmıştır (08.12.2016 tarihli 7 sayılı oturumun 36 nolu kararı ile).

Çalışma popülasyonu: Hastanemiz acil servisinden 01.01.2010- 01.12.2016 tarihleri arasında akut apandisit tanısı konularak genel cerrahi kliniğine yatırılan hastalar incelendi. Hastaneye yatırıldıktan sonra AA tanısı ile opere edilen hastalar [AA $(+)$ ] çalışma gru$\mathrm{bu}$, takip sonrası opere edilmeyip taburcu edilen hastalar [AA (-)] kontrol grubu olarak çalışmaya dahil edildi.

Dahil etme ve dışlama kriterleri: On altı yaş üstü, inflamatuvar başka bir hastalığı olmayan, elektronik sistemden tüm verilerine, hasta dosyalarına ulaşabildiğimiz hastalar çalışmaya dahil edildi. Malignite, gebelik, immün yetmezlik, bilinen böbrek, karaciğer fonksiyon bozukluğu yapacak durumlar, inflamatuvar barsak hastalıkları ya da inflamatuvar başka durumlar hastaların hemogram parametrelerinde fizyolojik farklılıklara yol açabileceği için bu hastalar da dışlandı.
Klinik gözlemi esnasında taburculuk talebi olan hastalar son durumlarını takip edemediğimiz için çalışmadan çıkarıldı. AA $(+)$ grupta değerlendirilen bazı hastaların operasyon notlarından ya da yatış epikrizlerinden başka bir akut batın nedeni ile opere olanlar çalışmanın konusu dışında oldukları için çalışmadan çıkarıldı. Dahil etme kriterlerine uymayan, elektronik dosyalarından tedavinin, gözlemin devamını kabul etmediği anlaşılan hastalar çalışmadan çıkarıldı. Dışlama ve dahil etme kriterlerinin uygulanması sonucunda 1061 hasta çalışmaya dahil edildi.

Verilerin elde edilmesi: Acil servise başvuran hastalardan hemogram testi çalışılması için alınan kanlar acil servis içerisinde, EDTA'lı tüplere alınmaktadır. Hemogram örnekleri laboratuvara hastanemizdeki pnömotik sistemle ulaştırılmaktadır. Hastanemizde hemogram spesifik Sysmex marka cihaz kullanılmaktadır. Çıkan sonuçlar elektronik hasta dosyasına aktarılmaktadır. Bu çalışmada hastaların acil servise başvuru anındaki hemogram sonuçları incelenmiştir. Hastaların acil servise başvuru anındaki hemogram sonuçlarına hastane bilgi yönetim sisteminde kayıtlı elektronik dosyalarından ulaşılmıştır.

Istatistiksel analiz: Elde edilen veriler SPSS 20 paket programına kaydedilmiştir. Hastaların yaş, cinsiyet gibi demografik özellikleri, hemogram parametreleri, numerik veriler için ortalama \pm standart sapma, minimum - maximum, kategorik veriler için yüzde frekans analizi yapılmıştır. Çalışma ile kontrol grubu arasında numerik verilerin karşılaştırılmasında student $\mathrm{t}$ testi, kategorik verilerin karşılaştırılmasında ki kare testi uygulanmıştır. $\mathrm{P}$ değeri $<0.05$ anlamlı değer olarak kabul edilmiştir.

\section{Bulgular}

$\mathrm{Bu}$ çalışmada değerlendirilen 1061 hastanın \%46.6's1 kadın (494), \%53.4'ü (567) erkek hastalar olarak bulundu. Hastaların \%83.6's1 (888) AA (+), \%16.2'si (173) AA (-) grubundadır. Hastaların AA (+) gruptaki yaş ortalaması $(35 \pm 16)$ ile AA (-) gruptaki yaş ortalamaları (35 \pm 16$)$ bulundu (Tablo I).

AA (+) hasta grubu ile AA (-) hasta grubunun WBC oranları kıyaslandığında WBC değerleri, nötrofil değerleri AA (+) hasta grubunda istatistiksel olarak anlamlı, yüksekti $(\mathrm{P}<0.001, \mathrm{P}<0.001)$. MPV değerleri her iki grupta da referans değerler aralığındaydı. Her iki grup arasında MPV değerleri arasında anlamlı bir fark yoktu $(\mathrm{P}=0.717)$. PDW değerleri AA $(+)$ hasta grubunda istatistiksel olarak anlamlı, düşük bulundu $(\mathrm{P}=0.007)$ (Tablo I). 
Tablo I. Gruplara ait hemogram parametreleri ve demografik özelliklerin istatistiksel değerlendirmesi.

\begin{tabular}{|c|c|c|c|c|c|}
\hline & $\begin{array}{c}\text { AA (+) } \\
\text { MEAN } \pm \text { SD }\end{array}$ & $\begin{array}{c}\text { AA(-) } \\
\text { MEAN } \pm \\
\text { SD }\end{array}$ & $\stackrel{P}{\text { DEĞERi }}$ & $\begin{array}{c}\text { TOPLAM } \\
\text { MEAN } \pm \\
\text { SD }\end{array}$ & $\begin{array}{l}\text { REFERA } \\
\text { NS } \\
\text { ARALIĞ }\end{array}$ \\
\hline YAŞ & $35 \pm 16$ & $35 \pm 16$ & 0,870 & $35 \pm 16$ & \\
\hline WBC $\left({ }^{*} 10^{3} \mu L\right)$ & $13,5 \pm 4,5$ & $11,5 \pm 5$ & $<0,001$ & $13,2 \pm 4,70$ & $4,3-10,3$ \\
\hline $\begin{array}{l}\text { LENFOSIT ( }{ }^{*} 10^{3} \\
\text { pl) }\end{array}$ & $1,94 \pm 1$ & $1,98 \pm 0,9$ & 0,613 & $2 \pm 1$ & $1,3-3,6$ \\
\hline $\begin{array}{l}\text { EOZiNOFiL } \\
(\mu \mathrm{L})\end{array}$ & $0,09 \pm 0,17$ & $0,13 \pm 0,16$ & 0,014 & $0,1 \pm 0,2$ & \\
\hline MONOSIT ( $\mu \mathrm{L}$ ) & $0,9 \pm 0,9$ & $0,78 \pm 0,7$ & 0,107 & $0,9 \pm 0,9$ & $0,3-0,9$ \\
\hline $\begin{array}{l}\text { NÖTROFiL } \\
\left({ }^{*} 10^{3} \mu \mathrm{L}\right)\end{array}$ & $10,56 \pm 4,43$ & $8,25 \pm 3,73$ & $<0,001$ & $10,1 \pm 4,4$ & $2,1-8,1$ \\
\hline BAZOFIL ( $\mu L)$ & $0,99 \pm 0,35$ & $0,08 \pm 0,31$ & 0,576 & $0,1 \pm 0,4$ & $0-0,2$ \\
\hline $\begin{array}{l}\text { PLATELET } \\
\left({ }^{*} 10^{3} \mu \mathrm{L}\right)\end{array}$ & $251 \pm 65$ & $250 \pm 72$ & 0,907 & $251 \pm 67$ & $150-450$ \\
\hline MPV (fL) & $8,5 \pm 1,3$ & $8,6 \pm 1,2$ & 0,717 & $8,6 \pm 1,3$ & $6,8-10,8$ \\
\hline PDW & $15,6 \pm 2,5$ & $16 \pm 1,9$ & 0,007 & $15,7 \pm 2,4$ & $10-14$ \\
\hline
\end{tabular}

AA: Akut apandisit, WBC: White blood cells, HGB: hemoglobin, HTC: hematokrit değeri, MCV: mean corpusculer volume, $\mathrm{MCH}$ mean corpusculer hemoglobin, MCHC:mean corpusculer hemoglobin concentration, RBC: red blood cells, RDW: red cell distrubition width, PDW: platelet distrubition width, MPV:mean platelet volüme, PCT: platectrin, NLR: nötrofil lenfosit ratio, PLR: platelet lenfosit ratio.

$\mathrm{Bu}$ çalışmada incelediğimiz grupların cinsiyete göre analizi yapıldı. Çalışmamıza dahil edilen kadın hastalarda AA (+) hasta grubu ile AA (-) hasta grubunun karşılaştırılmasında AA $(+)$ hasta grubunda; WBC yüksek, bu yükseklik istatistiksel olarak anlamlı $(\mathrm{P}<0.001)$ idi. Nötrofil değerleri AA $(+)$ hasta grubunda yüksek ve istatistiksel olarak anlamlı bulundu $(\mathrm{P}<0.001)$. Aynı grupta PDW değeri düşük, istatistiksel olarak anlamlı $(\mathrm{P}=0.001)$ bulundu. MPV değeri gruplar arasında anlamlı değildi ( $\mathrm{P}=0.743)$ (Tablo II).
Erkek hastalar için oluşturulan AA (+) ve AA (-) alt grupları kıyaslandığında AA (+) hasta grubunda; WBC değeri üst sınırdan yüksek, bu yükseklik istatistiksel olarak anlamlı bulundu $(\mathrm{P}=0.02)$. Nötrofil değeri üst sınırdan yüksek, bu yükseklik istatistiksel olarak anlamlı $(\mathrm{P}<0.001)$ bulundu. MPV, PDW değerleri için gruplar arasında anlamlı fark bulunamadı (Tablo II).

\section{Tartışma ve Sonuç}

Bu çalışma, acil servise karın ağrısı şikayetiyle başvuran, AA tanisı ile opere olan hastalar ile cerrahi tedavi yapılmadan taburcu edilen hastaların ayırıcı tanısında MPV ve PDW parametrelerinin rolünün araştırılması amacıyla yapılmıştır. Çalışmamızda, WBC oranları kıyaslandığında WBC ve nötrofil değerleri AA (+) hasta grubunda daha yüksek ve istatistiksel olarak anlamlı iken MPV değerleri arasında istatistiksel anlamlı bir fark bulunamamıştır. PDW değerleri ise AA (+) hasta grubunda daha düşük ve istatistiksel olarak anlamlı bulunmuştur.

Günümüzde halen AA tanısı için birçok farklı biyobelirteç araştırılmaktadır. Çalışılan biyobelirteçlerin bir kısmı oldukça pahalı, bir kısmı da acil servisler için kullanışsızdır. Klinisyenlerin en sık faydalanmaya çalıştığı biyobelirteçler inflamatuvar belirteçlerdir ${ }^{8}$. İnflamatuvar süreçlerden etkilenen, rutinde kullanılan basit ve ucuz bir yöntemle elde edilen MPV ve PDW değerleri de bunlardandır. Yapılan çalışmalarda MPV ve PDW ile ilgili birbirinden farklı sonuçlar elde edilmiştir. Bu farklılık inflamasyonun süresi, derecesi ya da hastalarda başka bir inflamatuvar durumun varlığı ile ilişkili olabilir. Ayrıca inflamatuvar olayların meydana gelişi sırasında değişen sitokin seviyeleri megakaryopoezi ve trombositlerin boyutunu etkiler ${ }^{9,10}$. Küçük ve arkadaşlarının yaptığı retrospektif bir çalışmada, AA tanısı alan hastalarda MPV anlamlı olarak

Tablo II. Cinsiyete göre gruplar arasında hemogram parametrelerinin istatitiksel analizi

\begin{tabular}{|c|c|c|c|c|c|c|c|}
\hline & $\begin{array}{l}\mathrm{AA}(+) \text { Kadın Mean } \pm \\
\text { SD }\end{array}$ & $\begin{array}{l}\text { AA(-) Kadın } \\
\text { Mean } \pm \text { SD }\end{array}$ & P DEĞERI & $\begin{array}{l}\text { AA(+) Erkek } \\
\text { Mean } \pm \text { SD }\end{array}$ & $\begin{array}{l}\text { AA(-) Erkek } \\
\text { Mean } \pm \text { SD }\end{array}$ & P DEĞERI & $\begin{array}{l}\text { REFERANS } \\
\text { ARALIĞI }\end{array}$ \\
\hline Yaş & $35 \pm 15$ & $37 \pm 18$ & 0.276 & $34 \pm 15$ & $32 \pm 14$ & 0.251 & \\
\hline WBC $\left({ }^{*} 10^{3} \mu \mathrm{l}\right)$ & $13,1 \pm 4,4$ & $10,9 \pm 4$ & $<0,001$ & $13,96 \pm 4,55$ & $12,13 \pm 5,97$ & 0,002 & $4,3-10,3$ \\
\hline Lenfosit ( $\left.{ }^{*} 10^{3} \mu \mathrm{l}\right)$ & $1,9 \pm 1$ & $1,9 \pm 0,9$ & 0,869 & $1,96 \pm 0,97$ & $2,04 \pm 0,96$ & 0,506 & $1,3-3,6$ \\
\hline EozinofiL ( $\mu$ l) & $0,1 \pm 0,2$ & $0,1 \pm 0,1$ & 0,478 & $0,1 \pm 0,12$ & $0,2 \pm 0,19$ & 0,009 & \\
\hline Monosit ( $\mu \mathrm{l})$ & $0,9 \pm 1,1$ & $0,7 \pm 0,5$ & 0,160 & $0,94 \pm 0,8$ & $0,88 \pm 0,9$ & 0,564 & $0,3-0,9$ \\
\hline Nötrofil (*103 $\mu \mathrm{l})$ & $10,2 \pm 4,4$ & $8 \pm 3,7$ & $<0,001$ & $10,9 \pm 4,4$ & $8,5 \pm 3,7$ & $<0,001$ & $2,1-8,1$ \\
\hline Bazofil ( $\mu \mathrm{l})$ & $0,1 \pm 0,4$ & $0,06 \pm 0,1$ & 0,360 & $0,1 \pm 0,3$ & $0,1 \pm 0,5$ & 0,797 & $0-0,2$ \\
\hline Platelet $\left({ }^{*} 10^{3} \mu \mathrm{l}\right)$ & $264 \pm 71$ & $256 \pm 73$ & 0,310 & $240 \pm 60$ & $244 \pm 71$ & 0,64 & $150-450$ \\
\hline MPV (fl) & $8,7 \pm 1,4$ & $8,6 \pm 1,1$ & 0,743 & $8,4 \pm 1,2$ & $8,6 \pm 1,3$ & 0,489 & $6,8-10,8$ \\
\hline PDW & $15,5 \pm 2,6$ & $16,2 \pm 1,6$ & 0,001 & $15,6 \pm 2,5$ & $15,8 \pm 2,2$ & 0,523 & $10-14$ \\
\hline
\end{tabular}

AA: Akut apandisit, WBC: White blood cells, HGB: hemoglobin, HTC: hematokrit değeri, MCV: mean corpusculer volume, MCH: mean corpusculer hemoglobin, MCHC: mean corpusculer hemoglobin concentration, RBC: red blood cells, RDW: red cell distrubition width, PDW: platelet distrubition width, MPV: mean platelet volüme, PCT: platectrin, NLR: nötrofil lenfosit ratio, PLR: platelet lenfosit ratio. 


\section{F. Tortum ve A. Bayramoğlu}

düşük bulunmuştur. Akut inflamatuvar durumların MPV değerinde düşüşe neden olduğunu ve AA tanılı hastalarda mevcut olan akut inflamasyonun MPV değerinin düşük çıkmasına neden olduğu vurgulanmıştır ${ }^{11}$. Bu çalışmanın aksine, literatürdeki bazı çalışmalarda ise MPV değerleri AA tanılı hastalarda daha yüksek bulunmuştur ${ }^{12-14}$. Bu çalışmalardan Daldal ve arkadaşlarının yaptığı çalışmada kontrol grubu olarak patoloji rapor sonucu lenfoid hiperplazi olan hastalar seçilirken, Narcı ve arkadaşları ise kontrol grubunu sağlıklı gönüllülerden oluşturmuştur. $\mathrm{Bu}$ da çalışmalarda kontrol grubu seçiminin MPV değerinde değişikliklere neden olabileceğini göstermiştir. Bizim çalışmamızda ise, kontrol grubu AA ön tanısı ile yatırılmış ve opere edilmeden, medikal tedavi ile taburcu edilen hastalardan oluşturulmuştur. Her iki grupta da inflamatuvar durum mevcut olduğu için ve inflamatuvar durum trombositlerin boyutunu etkilediğinden MPV değerleri arasında anlamlı bir fark bulunamamiştır.

İnflamatuvar durumların trombosit aktivitesini, boyutunu etkilediği bilinmektedir. Bu nedenle PDW'nin AA tanısı koymak için değerlendirildiği birçok çalışma mevcuttur. Ancak bu çalışmalarda da sonuçlar çelişkilidir. Bazı çalışmalarda AA tanısı almış hastaların PDW değerleri yüksek bulunmuştur ${ }^{15-17}$. Bazı çalışmalarda ise AA hastaları ile kontrol gruplarının PDW değerleri arasında bir fark bulunmamıștır ${ }^{18,19}$. $\mathrm{Bu}$ çalışmaların aksine bizim çalışmamızda AA (+) hasta grubunda PDW değerleri düşük bulunmuştur. Çeşitli çalışmaların sonuçlarındaki tutarsızlık birkaç faktöre bağlanabilir. Bazı çalışmaların kontrol grubunun sağlıklı gönüllülerden seçilmiş olması, hastaların antikoagülan alıp almaması, çalışmaların çoğunun retrospektif doğası nedeniyle, çalışmalarda kan alma ve analiz süresi arasındaki sürenin standardize edilmemiş olması, kan alma tekniklerinde ve alınan kanın hemogram tüpüne doldurulması aşamasındaki uygulamaların farklı olması gibi durumlar trombosit aktivitelerinde, morfolojilerinde değişikliğe neden olmuş olabilir.

Aydoğan ve arkadaşları tarafından yapılan çalışmanın alt grupları ise perfore olan ve olmayan hastalardan oluşturulmuştur. Perfore olan grupta PDW değeri perfore olmayan gruba göre yüksek bulunmuştur. Ancak MPV değeri perfore olan hasta grubunda perfore olmayan hasta grubuna göre daha düşük bulunmuş$\operatorname{tur}^{17}$. Ceylan ve arkadaşlarının yaptığı çalışmada MPV değerleri komplikasyonsuz AA grubunda komplikasyonlu AA grubu ve sağlıklı gönüllülerin oluşturduğu gruplardan daha düşük bulunmuştur. PDW değeri için gruplar arasında herhangi bir fark bulunamamıştır ${ }^{19}$. Bizim çalışmamızda komplike olan, perfore olan hastalar ayrı ayrı gruplandırılmamış olup bu hastalar AA tanısı ile opere edilen hastalar içerisinde değerlendirilmiştir. Ancak diğer çalışmalardan anlaşıldığı kadarıyla uzamış, komplike olmuş vakalarda kronik infla- matuvar reaksiyonlara benzer şekilde megakaryopoez etkilenmektedir. $\mathrm{Bu}$ nedenle inflamatuvar sürecin uzunluğu MPV ve PDW değerleri üzerinde etkili olacağı kanaatindeyiz.

Yang ve arkadaşlarının yaptığı çalışmada AA tanısı alan hastalar cinsiyetlerine göre alt gruplara ayrılmış, bu durumda erkek hasta grubunda MPV değerlerinde anlamlı bir azalma olduğu görülmüş ve istatistiksel olarak anlamlı olduğu vurgulanmıştır $(\mathrm{P}=0.009)^{20}$. Bizim çalışmamızda erkek AA (+) hastaların ayırıcı tanısında hem MPV hem de PDW değeri anlamsız bulunmuşken kadın AA (+) hastalarda yalnızca PDW değeri anlamlı bulunmuştur. Kadınlarda pelvik inflamatuvar durum gibi inflamatuvar, jinekolojik hastalıkların bu sonuca neden olmuş olabileceği kanaatindeyiz. Akut apandisit tanısı amacıyla en sık kullanılan parametrelerden biri de WBC değerleridir. Birçok çalışmada AA tanısı alan hastalarda WBC değerleri kontrol gruplarından daha yüksek ve istatistiksel olarak anlamlı bulunmuştur ${ }^{10,12,15}$. Literatüre benzer şekilde bu çalışmada da AA tanısı ile opere edilen hastaların WBC değerleri kontrol grubundan yüksek bulunmuştur.

Çalışmamızın kısıtlılıkları; çalışmanın retrospektif olması, AA (-) hasta grubu sayısının AA (+) hasta grubundan düşük olması, tek merkezli bir çalışma olması çalışmayı sınırlandıran faktörler olmuştur. Daha geniş hasta grupları ile yapılacak prospektif çalışmalara ihtiyaç vardır.

AA (+) hasta grubu ile AA (-) hasta grubunu birbirinden ayırmak için MPV'nin anlamsız olduğu görülmüştür. PDW değerleri AA (+) hasta grubunda düşük ve anlamlı bulunmuştur. Ancak AA $(+)$ grubunun PDW değeri ile kontrol grubu arasında belirgin sayısal fark gözlenmemiştir. $\mathrm{Bu}$ nedenle PDW değerinin klinik kullanımı yeni, daha geniş hasta grubuna sahip çalışmalarla desteklenmelidir. Ayrıca literatürdeki diğer çalışmalara benzer şekilde AA $(+)$ hasta grubunda WBC, nötrofil düzeyleri yüksek olarak bulunmuştur. $\mathrm{Bu}$ nedenle WBC, nötrofil düzeyleri hastaların AA nedeni ile opere olması gerektirecek kadar appendiks inflamasyonu olduğu hakkında klinisyene yol gösterici olabilir. Ancak MPV ve PDW değerlerinin bu amaçla kullanımı uygun olmayacaktır.

\section{Etik Kurul Onay Bilgisi:}

Onaylayan Kurul: Atatürk Üniversitesi Tıp Fakültesi Klinik Araştırmalar Etik Kurulu

Onay Tarihi: 08.12 .2016

Karar No: 36

\section{Araştırmacı Katkı Beyanı}

"Fikir ve tasarım: F.T., A.B.; Veri toplama ve ișleme: F.T.; Analiz ve verilerin yorumlanması: A.B.; Makalenin önemli bölümlerinin yazılması: F.T."

Çıkar Çatışması Beyanı:

Makale yazarlarının çıkar çatışması beyanı yoktur. 


\section{Kaynaklar}

1. Addiss DG, Shaffer N, Fowler BS, Tauxe RV. The epidemiology of appendicitis and appendectomy in the United States. American journal of epidemiology. 1990;132(5):910-25.

2. Andersson R. Meta-analysis of the clinical and laboratory diagnosis of appendicitis. British journal of surgery. 2004;91(1):28-37.

3. R Kiziltan, AR Karayil, A Aras, et al. Are Appendix Weight and Length Related to Inflammatory Parameters and Alvarado Score in Acute Appendicitis?. Eastern Journal Of Medicine. 2021;26(2): 248-254.

4. Osselaer JC, Jamart J, Scheiff JM. Platelet distribution width for differential diagnosis of thrombocytosis. Clin Chem. 1997;43(6 Pt 1):1072-6.

5. Vagdatli E, Gounari E, Lazaridou E, et al. Platelet distribution width: a simple, practical and specific marker of activation of coagulation. Hippokratia. 2010;14(1):28-32.

6. Jagroop IA, Clatworthy I, Lewin J, Mikhailidis DP. Shape change in human platelets: measurement with a channelyzer and visualisation by electron microscopy. Platelets. 2000;11(1):28-32.

7. Narci H, Turk E, Karagulle E, et al. The role of mean platelet volume in the diagnosis of acute appendicitis: a retrospective case-controlled study. Iran Red Crescent Med J 2013;15(12):e11934.

8. Flum DR. Clinical practice. Acute appendicitis--appendectomy or the "antibiotics first" strategy. $N$ Engl $J$ Med. 2015;372(20):1937-43.

9. Schellekens DH, Hulsewé KW, van Acker BA, et al. Evaluation of the diagnostic accuracy of plasma markers for early diagnosis in patients suspected for acute appendicitis. Academic Emergency Medicine. 2013;20(7):703-10.

10. Boshnak N, Boshnaq M, Elgohary H. Evaluation of platelet indices and red cell distribution width as new biomarkers for the diagnosis of acute appendicitis. Journal of Investigative Surgery. 2018;31(2):121-9.

11. KucuK E, KucuK I. Mean platelet volume is reduced in acute appendicitis. Turkish journal of emergency medicine. 2015;15(1):23-7.

12. Daldal E, Dagmura H, editors. The correlation between complete blood count parameters and appendix diameter for the diagnosis of acute appendicitis. Healthcare; 2020: Multidisciplinary Digital Publishing Institute.

13. Aktimur R, Cetinkunar S, Yildirim K,et al. Mean platelet volume is a significant biomarker in the differential diagnosis of acute appendicitis. Inf Cell Sig. 2015;2:e930.

14. Narci H, Turk E, Karagulle E, et al. The role of mean platelet volume in the diagnosis of acute appendicitis: a retrospective case-controlled study. Iran Red Crescent Med J. 2013;15(12):e11934.

15. Fan Z, Pan J, Zhang Y, et al. Mean platelet volume and platelet distribution width as markers in the diagnosis of acute gangrenous appendicitis. Disease markers. 2015;2015.

16. Albayrak Y, Albayrak A, Albayrak F, et al. Mean platelet volume: a new predictor in confirming acute appendicitis diagnosis. Clinical and Applied Thrombosis/Hemostasis. 2011;17(4):362-6.

17. Aydogan A, Akkucuk S, Arica S, et al. The analysis of mean platelet volume and platelet distribution width levels in appendicitis. Indian Journal of Surgery. 2015;77(2):495-500.

18. Dinç T, Şenol K, Yıldız BD, et al. Association between red cell distribution width and mea platelet volume with appendicitis: A myth or a fact? 2015.

19. Ceylan B, Aslan T, Çınar A, et al. Can platelet indices be used as predictors of complication in subjects with appendicitis? Wiener klinische Wochenschrift. 2016;128(8):620-5.

20. Yang JJ, Cho SY, Ahn H-J, et al. Mean platelet volume in acute appendicitis: a gender difference. Platelets. 2014;25(3):226-7. 
